\title{
INFLUENCE OF FIN'S MATERIAL CAPABILITIES ON THE PROPULSION SYSTEM OF BIOMIMETIC UNDERWATER VEHICLE
}

\author{
Pawel Piskur \\ Piotr Szymak \\ Zygmunt Kitowski \\ Leszek Flis \\ Polish Naval Academy, Gdynia, Poland
}

\begin{abstract}
The technology of Autonomous Underwater Vehicles (AUVs) is developing in two main directions focusing on improving autonomy and improving construction, especially driving and power supply systems. The new Biomimetic Underwater Vehicles (BUVs) are equipped with the innovative, energy efficient driving system consisting of artificial fins. Because these driving systems are not well developed yet, there are great possibilities to optimize them, e.g. in the field of materials. The article provides an analysis of the propulsion force of the fin as a function of the characteristics of the material from which it is made. The parameters of different materials were used for the fin design and their comparison. The material used in our research was tested in a laboratory to determine the Young's modulus. For simplicity, the same fin geometry (the length and the height) was used for each type of fin. The Euler-Bernoulli beam theory was applied for estimation of the fluid-structure interaction. This article presents the laboratory test stand and the results of the experiments. The laboratory water tunnel was equipped with specialized sensors for force measurements and fluid-structure interaction analysis. The fin deflection is mathematically described, and the relationship between fin flexibility and the generated driving force is discussed.
\end{abstract}

Keywords: fin flexibility, propulsion force, biomimetic underwater vehicle, fish-like movement

\section{INTRODUCTION}

Biomimetic Underwater Vehicles (BUVs) [8], [11] have become more popular due to their ability to achieve a low hydroacoustic spectrum [10] and high energy efficiency in comparison to Underwater Vehicles (UVs) [13] with conventional rotary propellers. The control algorithm is based on the movement of fish, especially on their undulating propulsion [7]. Fig. 1 shows the BUV with undulating propulsion made of a combination of rigid movable elements and flexible fins. This type of construction is difficult to control, quite expensive, and more connections increase the risk of flooding electronic components inside. Therefore, efforts have been made to investigate energy efficiency and the ability to achieve high linear speed for a vehicle with a propulsion system based on a one-piece flexible fin construction [20]. An example of an undulating propulsion system in a BUV in the form of one flexible fin is shown in Fig. 2. It was assumed that the fish-like movement could be reproduced with a fin made from a flexible material controlled with different motion algorithms. Fish-like movements seems to be more energetically efficient due to many million years of fish evolution. But it is difficult to reproduce due to the variable thickness along the fish body, the bone density and stiffness. A comprehensive review of the state of the art of hydrodynamics of the flapping foil is performed in the paper [19]. Although the review [19] is based on a large number of studies, it seems that many problems are still not completely understood, for example, how the flapping foil reverses the Kármán street or how to generate the optimal thrust. According to results presented in the papers [1], [14], flexibility plays a crucial role in determining the efficiency of 
undulating propellers. In the paper [4], it is assumed that the optimal oscillation frequency is different from the resonance frequency. In the paper [2], information is provided that it is possible to put the oscillation frequency for the range of optimal Strouhal number [17].

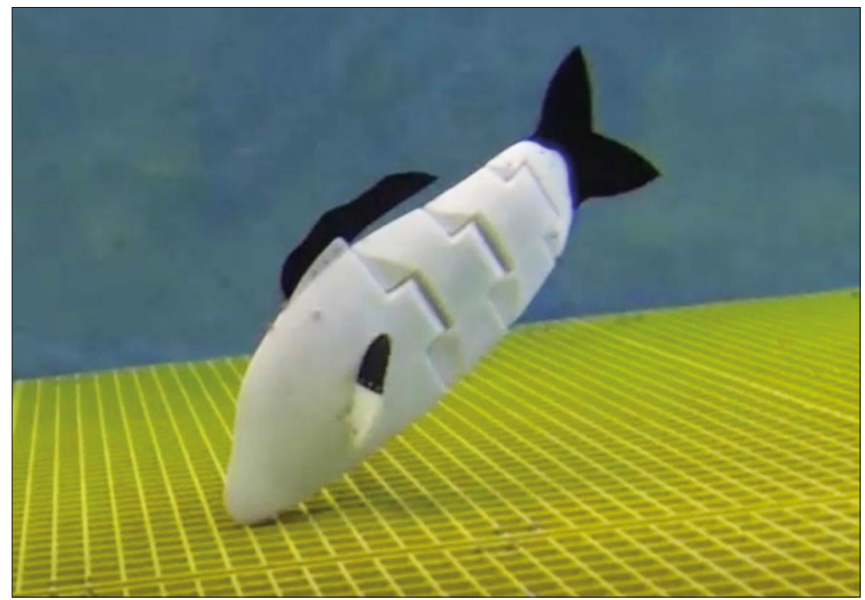

Fig. 1. Biomimetic underwater vehicle called CyberFish [7]

The fluid-structure interaction has an impact on the fin deflection and the amplitude of the trailing edge. The trailing edge amplitude depends on the angle of the attack, the actual speed, the length of the fin as well as the fin flexibility [1]. For a higher water velocity [12], the bending moment is higher, and the amplitude of the trailing edge is lower. Taking into consideration a nonlinear characteristic of generated thrust [16], the analysis is to be provided to determine the mutual, selected relationships between parameters of the undulating propulsion. Here, the fin flexibility and material capability impact on the produced propulsion force is investigated. The presented results were achieved for transient conditions but without water flow.

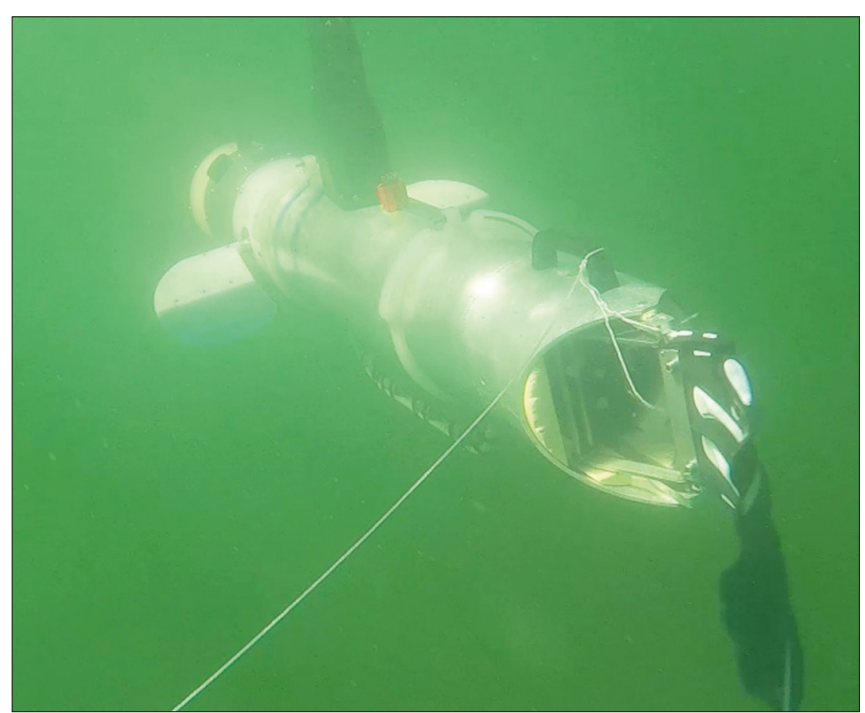

Fig. 2. BUV with two side fins and one flexible tail fin [15]

This paper is organized as follows. Section 2 discusses the mathematical model with the Euler-Bernoulli beam theory applied to the fin deflection analysis. Section 3 describes laboratory equipment and experimental results of the Young's modulus estimation as well as the force measurements. Section 4 provides a discussion on achieved experimental results. Finally, conclusions and the schedule of future research are presented in Section 5.

\section{MATHEMATICAL MODEL}

Taking into consideration the single-fin design for the BUV propulsion system, the Lighthill [6] model (1) can be used for its kinematic analysis:

$$
y(x, t)=\left(c_{1} x+c_{2} x^{2}\right) \sin (k x+\omega t)
$$

where:

$y(x, t)$ - the transverse displacement of the tail unit;

$x \quad-$ the independent spatial variable;

$t \quad-$ time, a second independent variable;

$c_{1} \quad-$ the primary coefficient of the fish wave envelope;

$c_{2} \quad-$ the quadratic term coefficient of the fish wave envelope;

$k=2 \pi / \lambda-$ the wave number;

$\lambda-$ the wavelength of the fish body;

$\omega=2 \pi f-$ the frequency of the fish wave.

The algorithm for the identification process of the coefficients $c_{1}$ and $c_{2}$ is presented in the author's paper [3].

The experiment was conducted for the same Reynolds number understood as a ratio of fluid inertia to viscous forces:

$$
R e=\frac{L \cdot v}{\gamma}
$$

where:

$$
\begin{array}{ll}
v & \text { - fluid velocity; } \\
\gamma & \text { - fluid viscosity; } \\
L & \text { - characteristic dimension. }
\end{array}
$$

According to literature research [8] and fish movement analysis [9], the optimal Strouhal number [17] defined by equation (3) is in a range from 0.25 to 0.35 .

$$
S t=\frac{f A_{y}}{U_{x}}
$$

where:

St - the Strouhal number;

$f \quad-$ the oscillation frequency;

$U_{x} \quad-$ the fluid (water) velocity;

$A_{y} \quad$ - the peak-to-peak oscillation amplitude, measured at the trailing edge.

The fin trailing edge amplitude depends on the maximal angle of attack and the fin stiffness, defined as EI, where:

$$
\begin{array}{ll}
E & - \text { the Young's modulus; } \\
I & \text { - the moment of inertia. }
\end{array}
$$

In some analysis [5], the fin flexibility is defined as the ratio of the fin deflection on the trailing edge to the total length 
of the fin due to the triple value of the total mass of the fin (Fig. 3) attached to the trailing edge. The above formulation is simply presented in equation (4):

$$
H_{F}=\frac{L}{h}
$$

where:

$$
\begin{array}{ll}
L & - \text { the length of the fin; } \\
h & - \text { the fin deflection; } \\
m_{f} & - \text { the mass of the fin. }
\end{array}
$$

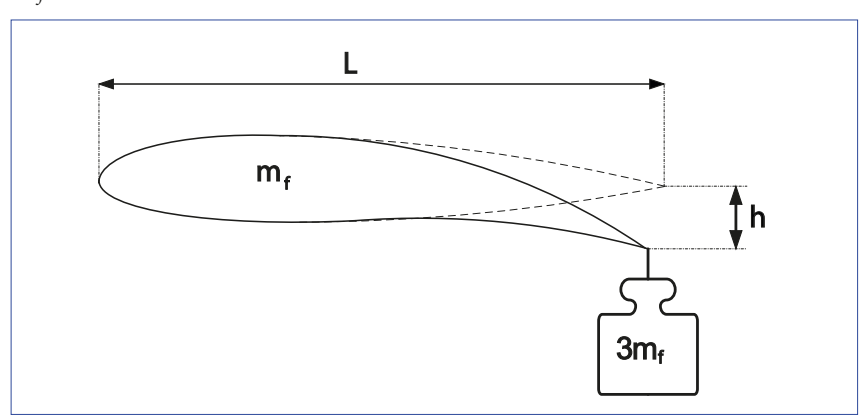

Fig. 3. Method of measuring the stiffness of a fin [18]

This simplification is insufficient if a more accurate mathematical model is required for the analysis of the dynamics of the system. To limit the number of influencing factors, the analysis was provided for fins with rectangular shape (Fig. 4). The fin dimension are length $L=100 \mathrm{~mm}$ and height $H=30 \mathrm{~mm}$, while the thickness $(w)$ depends on the material used. In this paper, the following fins were compared: the fin made from stainless steel with thickness $\mathrm{w}=0.1 \mathrm{~mm}$, the fin made from plexiglass with thickness $\mathrm{w}=0.5 \mathrm{~mm}$ and the fin made from PLA (polylactic acid) with thickness $\mathrm{w}=2 \mathrm{~mm}$.

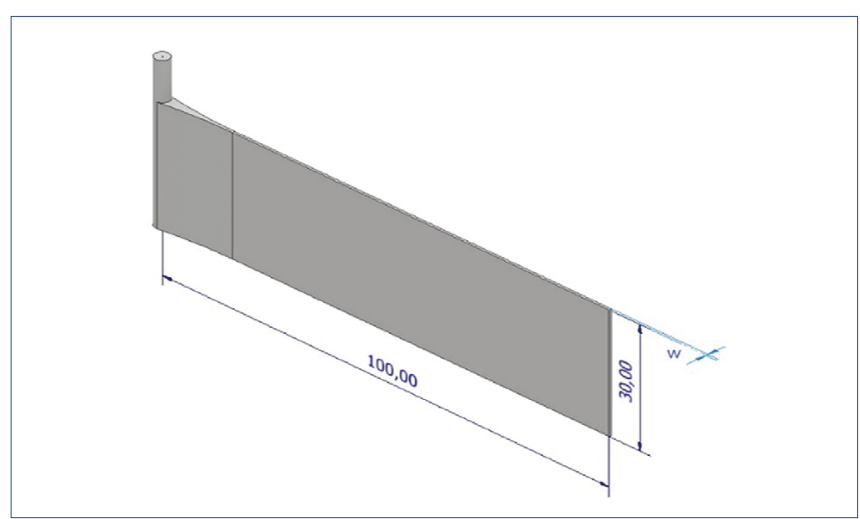

Fig. 4. Dimensions of the fins analysed in the thickness function (in w) of the material used

When considering the dynamics of the fin, the EulerBernoulli theory is to be taken into account [18]. Based on the partial differential equation (PDE), the propulsion force as a function of the fin deflection is described with equation (5):

$$
F=\frac{1}{2} \rho S\left\{\left(\frac{\partial y}{\partial t}\right)^{2}-U_{x}^{2}\left(\frac{\partial y}{\partial x}\right)^{2}\right\}_{x=L}
$$

where:

F $\quad-$ the propulsion force;

$y \quad-$ the coordinate perpendicular to $x$;
- the fluid density;

- the area of the fin cross section;

- the length of the fin;

- the independent spatial variable;

- the fluid velocity.

Due to the nonlinear interaction between fluid and the flexible fin, the following solution of equation (5) was proposed [4]:

$$
E I(x)=\frac{F(L-x)}{\frac{d^{2} \delta(x)}{d x^{2}}}
$$

where the deformation of the fin $\frac{d^{2} \delta(x)}{d x^{2}}$ was assigned from MES calculation. During the analysis, the deformation of the fin was established from the vision system described in the author's paper [3]. The stiffness depends on the moment of inertia $I$ and Young's modulus $E$. The relationship between the Young's modulus, the bending moment $M$ and the fin curvature $R$ can be written as follows:

$$
E I=M R
$$

where:

$M \quad$ - the bending moment;

E - the material modulus of elasticity (determined experimentally);

I - the moment of inertia about the axis of bending;

$R \quad-$ radius of the fin deflection.

In Fig. 5, according to equations (6) and (7), the fin deflection is presented for the value of force equal to $0.1 \mathrm{~N}$. Here, the force value is assumed, and the deflection is estimated using the analytic solution. According to Newton's third law of motion, if a fluid exerts force on a fin, a fin exerts force on a fluid so that the forces are equal but directed in opposite directions. Therefore, if the force needed to deform the fin can be estimated, then similarly the force acting on the fluid can be estimated based on the deflection of the fin. The red line represents the fin made from stainless steel $(\mathrm{w}=0.1 \mathrm{~mm}$ thickness), while the blue line is for the fin made from plexiglass ( $\mathrm{w}=0.5 \mathrm{~mm}$ thickness).

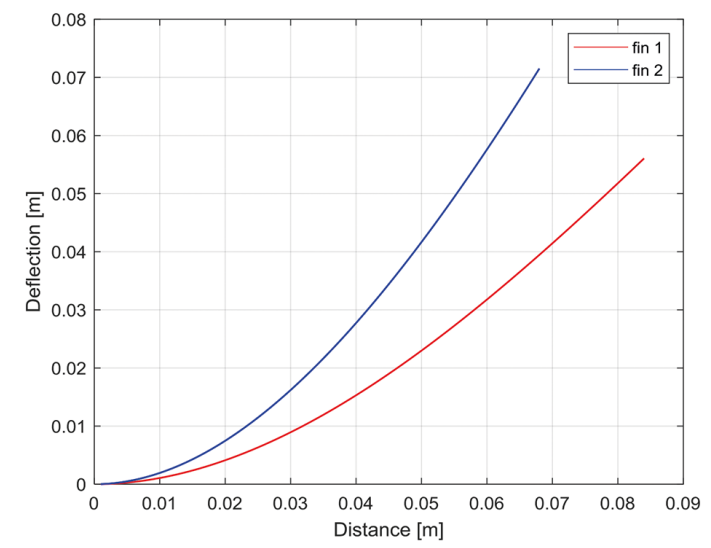

Fig. 5. The fin deflection for tested fins: fin 1 - made from stainless steel with the thickness $w=0.5 \mathrm{~mm}$, fin 2 - made from plexiglass with the thickness $w=0.1 \mathrm{~mm}$ 
In the next section the laboratory test stands are depicted for experimentally measurements of the fin material parameters and the force reaction in the water tunnel.

\section{LABORATORY TEST STANDS}

\section{WATER TUNNEL}

The water tunnel with measurement equipment is depicted in Fig. 6. Fins with different flexible properties were attached to the servomechanism (Dynamixel AX-12+). The servomechanism is attached to a transparent polycarbonate plate mounted on ball bearings above the water surface. Above the transparent plate, the camera was mounted for video recording of the fin deflection. The force between the fin and the water is measured by two precise strain gauges installed differentially on both sides of the water tunnel (Fig. 6).

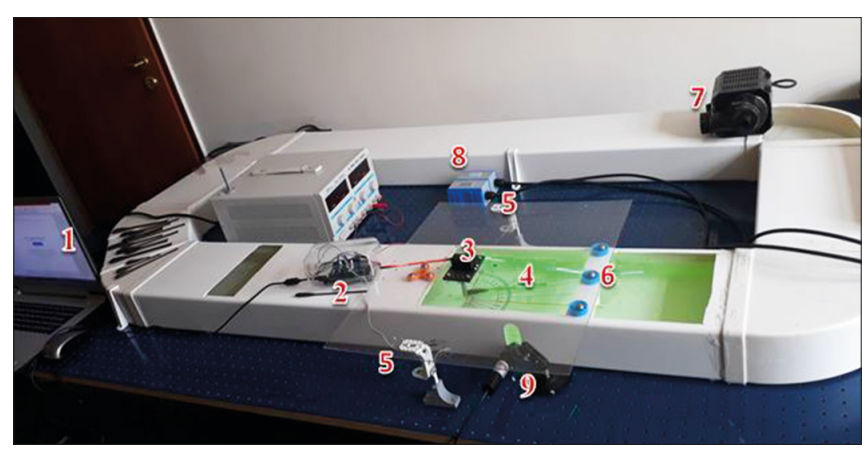

Fig. 6. Measurement test stand: 1 - computer, 2 - microcontroller, 3 - servomechanism, 4 - tested fin, 5 - strain gauges, 6 - ball bearings, 7 - water pump, 8 - ultrasonic flowmeter, 9 - laser

\section{THE YOUNG'S MODULUS ESTIMATION}

For the proper analysis, the material for the fin design was investigated with respect to mechanical parameters. Fig. 7 shows the laboratory station for measuring Young's modulus. Three kinds of materials were used for comparison between material properties and the fin flexibility. Although Young's modulus is well known for stainless steel, the designation of it for PLA material requires a lot of effort. In Fig. 9, the PLA material sample during the stretching test is presented.

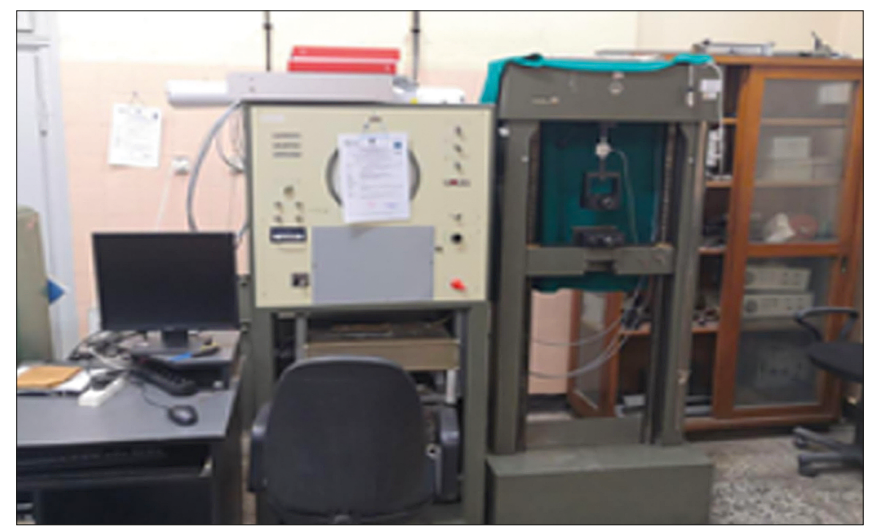

Fig. 7. Laboratory station for measuring Young's modulus

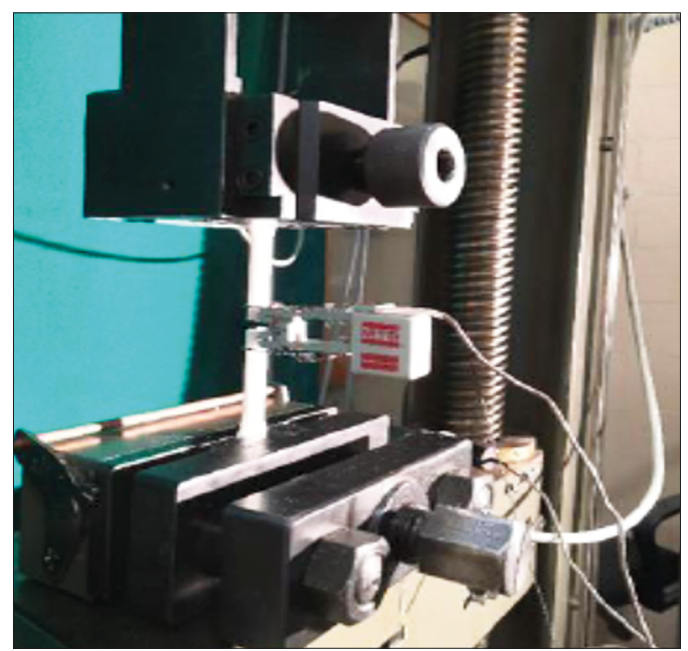

Fig. 8: The sample of material during stretching test

The results of experimental measurements of Young's modulus are depicted in Fig. 9. The equivalent engineering strain and stress were used to calculate Young's modulus. The following materials were selected for rapid prototyping of the fins for the propulsion system in the biomimetic underwater vehicle: PLA $(\mathrm{E}=2.90 \mathrm{GPa})$, plexiglass $(\mathrm{E}=3.25 \mathrm{GPa})$ and stainless steel $(\mathrm{E}=194 \mathrm{GPa})$. The first one was chosen because of possibility of three-dimensional printing with almost unlimited shape and dimensions of the fin. The second and the third ones were used because of their homogeneous material parameters and well-known mechanical parameters.

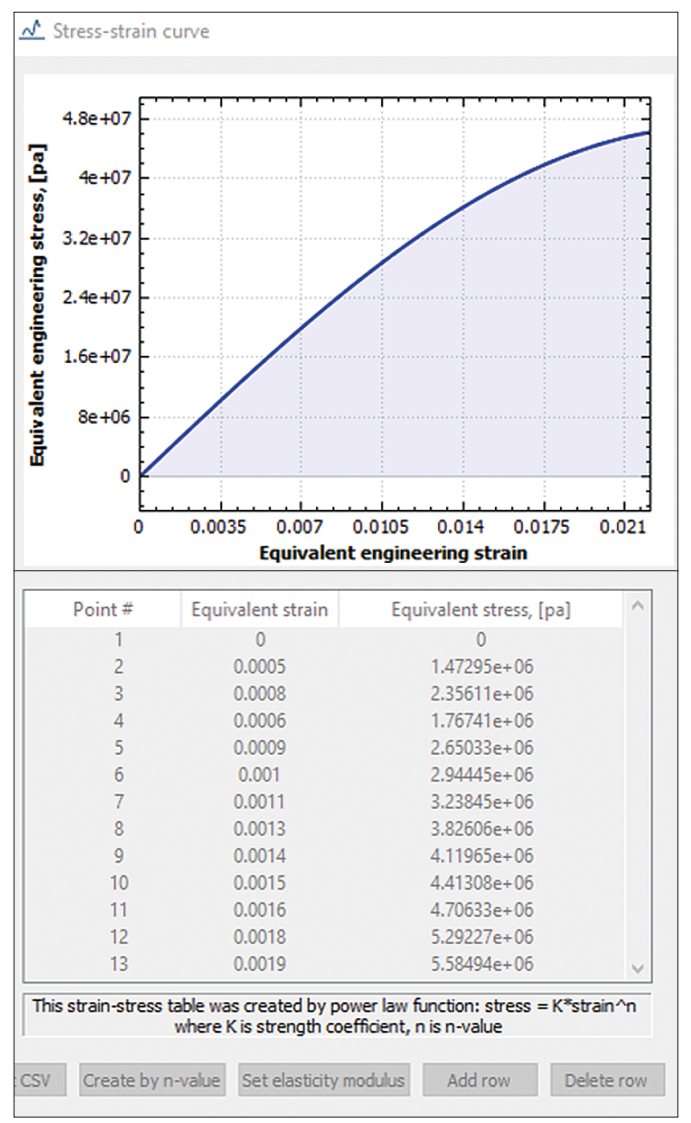

Fig. 9. The results achieved during the Young's modulus estimation as an approximation of the tangent of the slope of the curve 


\section{EXPERIMENTAL RESULTS}

The presented results of the experiment were provided for three fins with the same lateral surface but different thickness and material properties. Fins were driven with three different frequencies with the same angle of attack [11]. The amplitude of trailing edge can be used for the Strouhal number calculation (3) according to the vision system ability as presented in [3]. Here, the authors were focused on experimental thrust force measurements.

In Fig. 10, the force measured for the stainless steel fin with three frequencies $-f_{1}=0.7 \mathrm{~Hz}, f_{2}=1.4 \mathrm{~Hz}$ and $f_{3}=2.1 \mathrm{~Hz}$ - is presented. It can be observed that the largest oscillations were achieved for the lowest frequency. For the higher frequencies, the oscillations are lower and the mean thrust is higher. Therefore, the higher frequencies are desired for the BUV thrust if the stainless steel is considered as a material for fins.

In Fig. 11, the thrust is presented as a function of time for three different frequencies of fin propulsion. The fin is made from PLA material. It can be seen that the thrust increases proportionally to the control signal frequency, but the highest oscillation is observed for the second frequency.

In Fig. 12, the results for fin made from plexiglass are presented. For this fin, the largest force oscillations are observed for the lowest frequency $\left(f_{1}=0.7 \mathrm{~Hz}\right)$. For higher frequencies, the force increases and the oscillations decrease.

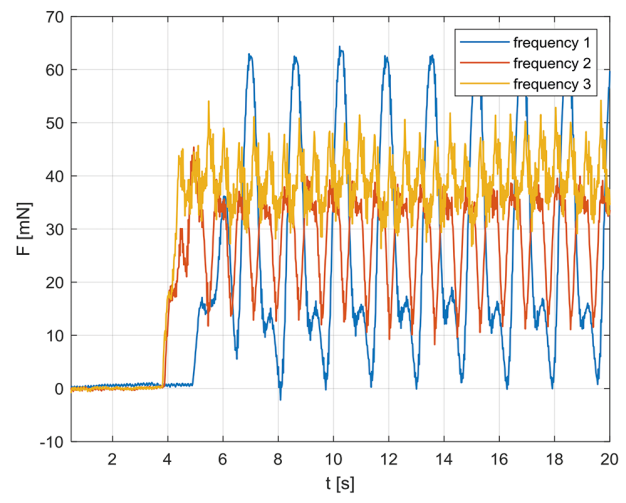

Fig. 10. Thrust for stainless steel fin propelled with three frequencies: $F_{\text {mean }}=27.5 \mathrm{~N}$ for $f_{1}=0.7 \mathrm{~Hz}, F_{\text {mean }}=28.1 \mathrm{Nforf}_{2}=1.4 \mathrm{~Hz}$, $F_{\text {mean }}=38.6 \mathrm{Nforf}_{3}=2.1 \mathrm{~Hz}$

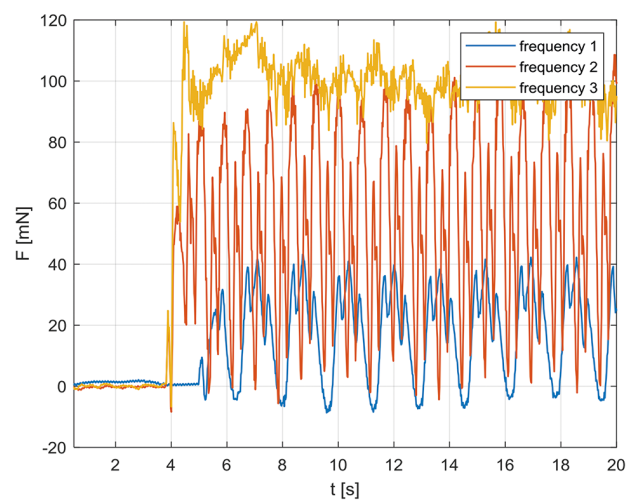

Fig. 11. Thrust for the fin made for PLA and propelled with three frequencies: $F_{\text {mean }}=18.2 \mathrm{Nforf}_{1}=0.7 \mathrm{~Hz}$, Fmean $=54.1 \mathrm{~N}$ for $_{2}=1.4 \mathrm{~Hz}$, $F_{\text {mean }}=98.2 \mathrm{Nforf}_{3}=2.1 \mathrm{~Hz}$

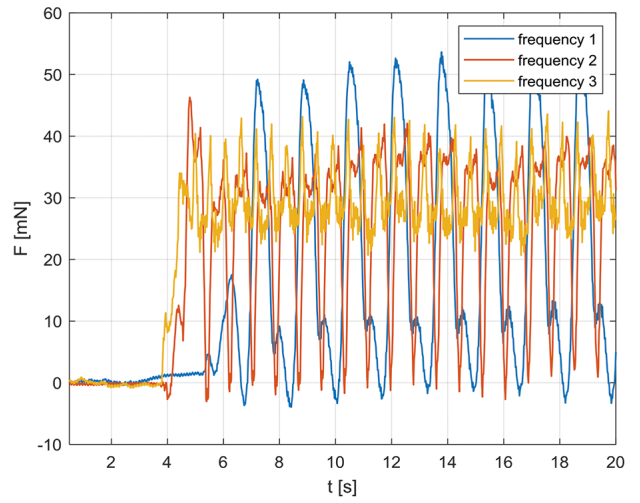

Fig. 12. Thrust for the fin made for plexiglass and propeller controlled with three frequencies: $F_{\text {mean }}=20.9 \mathrm{~N}$ for $\mathrm{fl}=0.7 \mathrm{~Hz}$,

$F_{\text {mean }}=25.7 \mathrm{Nfor}_{2}=1.4 \mathrm{~Hz}, F_{\text {mean }}=29.3 \mathrm{Nforf3}=2.1 \mathrm{~Hz}$

In Fig. 13 - Fig. 15, the experimentally measured force is presented for the same frequency but for different fins, i.e. fins with different flexibility. For the frequency $f_{1}=0.7 \mathrm{~Hz}$ (Fig. 13), the fin made from stainless steel has the highest oscillation and the highest mean thrust as well. The lowest thrust is produced by the fin made from PLA with $2 \mathrm{~mm}$ thickness.

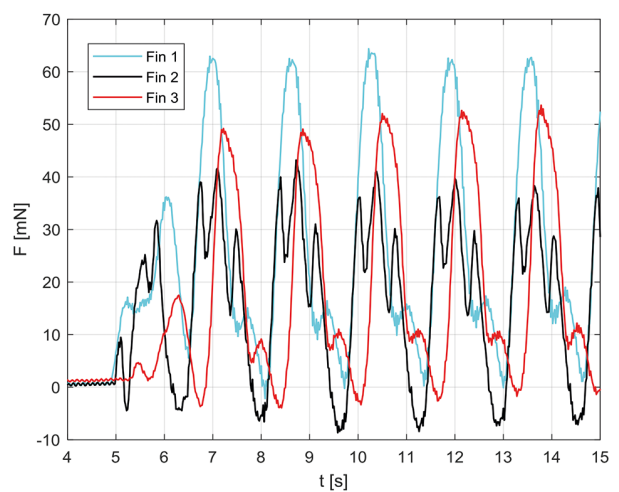

Fig. 13. Thrust produced by the three fins working with $f_{1}=0.7 \mathrm{~Hz}$ : $F=27.5 \mathrm{~N}$ for fin 1 (stainless steel), $F=18.2 \mathrm{~N}$ for fin 2 (PLA), $F_{\text {mean }}=20.9 \mathrm{~N}$ for fin 3 (plexiglas)

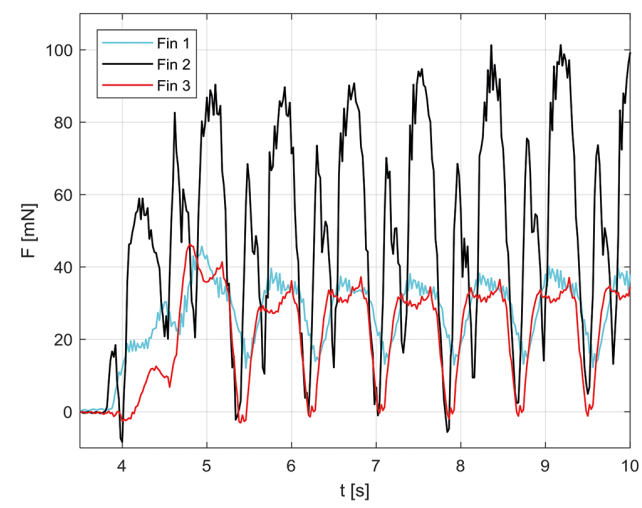

Fig. 14. Thrust produced by the three fins working with $f_{2}=1.4 \mathrm{~Hz}$ : $F_{\text {mean }}=28.1 \mathrm{~N}$ for fin 1 (stainless steel), Fmean $=54.1 \mathrm{~N}$ for fin 2 (PLA), $F_{\text {mean }}=25.7 \mathrm{~N}$ for fin 3 (plexiglas)

For the control frequency $f_{2}=1.4 \mathrm{~Hz}$, the highest mean thrust was achieved by the fin with the highest stiffness (Fig. 14). The stainless steel fin produced much less thrust 
than the fin made from PLA, but slightly higher thrust than the fin made from plexiglass.

For the frequency $f_{3}=2.1 \mathrm{~Hz}$ (Fig. 15), the fin with the lowest elasticity produced much higher force than other two fins. The oscillation level and the mean force are comparable with the fins made from PLA and from plexiglass.

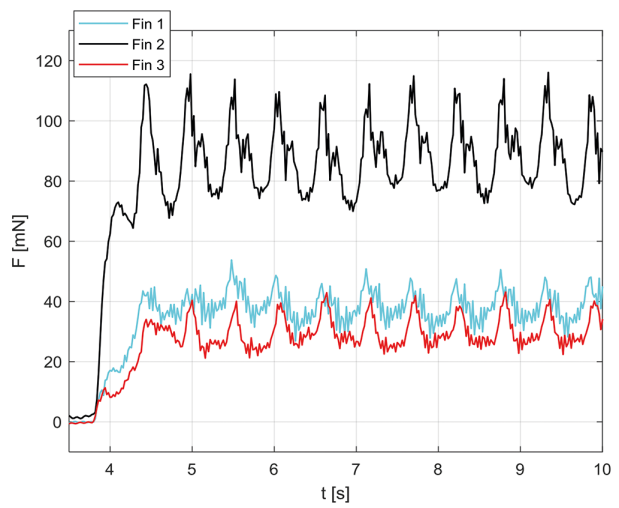

Fig. 15: Thrust produced by the three fins working with $f_{3}=2.1 \mathrm{~Hz}$ : $F_{\text {mean }}=38.6 \mathrm{~N}$ for fin 1 (stainless steel), $F_{\text {man }}=98.2 \mathrm{~N}$ for fin 2 (PLA), $F_{\text {mean }}=29.3 \mathrm{~N}$ for fin 3 (plexiglas)

The average values of thrust for all the fins and the frequencies tested are summarized in Table 1.

Tab. 1. Thrust produced by different fins oscillating with different frequencies

\begin{tabular}{|c|c|c|c|}
\hline & $\begin{array}{c}\text { Fin 1 } \\
w=0.1 \mathrm{~mm}, \\
\text { stainless steel } \\
E I=0.0005 \\
\mathrm{Nm}^{2}\end{array}$ & $\begin{array}{c}\text { Fin } 3 \\
\begin{array}{c}0.5 \mathrm{~mm}, \\
\text { plexiglas } \\
E I=0.0010 \\
\mathrm{Nm}^{2}\end{array}\end{array}$ & $\begin{array}{c}\text { Fin } 2 \\
=2 \mathrm{~mm}, \\
\text { PLA } \\
E I=0.0580 \\
\mathrm{Nm}^{2}\end{array}$ \\
\hline$f_{1}=0.7 \mathrm{~Hz}$ & $27.5 \mathrm{~N}$ & $20.9 \mathrm{~N}$ & $18.2 \mathrm{~N}$ \\
\hline$f_{2}=1.4 \mathrm{~Hz}$ & $28.1 \mathrm{~N}$ & $25.7 \mathrm{~N}$ & $54.1 \mathrm{~N}$ \\
\hline$f_{3}=2.1 \mathrm{~Hz}$ & $38.5 \mathrm{~N}$ & $29.3 \mathrm{~N}$ & $98.2 \mathrm{~N}$ \\
\hline
\end{tabular}

The presented results of measured force can be used not only for mean force value analysis but also for investigation of the influence of the fin oscillation frequencies. A natural frequency is the next factor that is to be taken into consideration. It is expected that the natural frequency of the fluid-structure model can be found, and the comparison to the literature value of the Strouhal number can be provided in the results of future research.

\section{CONCLUSIONS}

The fluid-structure interaction is a nonlinear problem without a ready-to-use mathematical model. The presented results can be used for a mathematical model verification, and they can establish the mathematical model validity range. The effort is to be made to connect the available EulerBernoulli beam theory with fluid mechanics. But even then, the mathematical model should be completed with the results from the measurements in a laboratory test stand. Based on the results of 2-mm-thick fin operation (the fin with highest value of $E I$ ). It can be shown that the analysed mathematical model validation range can be provided only for the flexible fin. If the inflexible fin is analysed, then fluid viscosity must be included and the mathematical model range validity analysis has to be additionally performed.

The goal of the paper was to examine how the mechanical parameters influence generated thrust. The presented results show not only the mean values of thrust force but also the oscillation of the force. It can be seen that the thrust produced by the fin depends not only on the fin flexibility but also on the frequency of the fin oscillation. What is more, the fluid viscosity has to be included due to the measurement results made for an inflexible fin. The water velocity is another factor that is to be taken into consideration in the next step of examining the fluid-structure interaction. In parallel, the fluid dynamics using Particle Imaginary Velocimetry (PIV) will be used for the examination of fluid viscosity in the transient state analysis. The results achieved are to be completed with an energy consumption investigation.

In future research, PLA material will be used because of the convenient way of designing variable shapes of fins. Then, the shape impact on generated thrust will be investigated.

\section{ACKNOWLEDGMENT}

The paper is supported by the Research Grant of the Polish Ministry of Defence entitled "Model studies of the characteristics of a undulating propulsion system".

\section{REFERENCES}

1. Behbahani S. B., Tan X. (2017). Role of pectoral fin flexibility in robotic fish performance, Journal of Nonlinear Science, 27, 1155-1181, https://doi.org/10.1007/ s00332-017-9373-6.

2. Tytella E. C., Hsu C.-Y., Fauci, L. J. (2014). The role of mechanical resonance in the neural control of swimming in fishes, Zoology, 117(1), 48-56, https://doi.org/10.1016/j. zool.2013.10.011.

3. Jurczyk K., Piskur P., Szymak P. (2020). Parameters identification of the flexible fin kinematics model using vision and genetic algorithms, Polish Maritime Research, 27(2), 39-47, https://doi.org/10.2478/pomr-2020-0025.

4. Kancharala A. K. (2015). The role of flexibility on propulsive performance of flapping fins, Doctor of Philosophy in Aerospace Engineering, Virginia Tech, Blacksburg, Virginia, https://doi.org/10919/56563.

5. Lauder G. V., Quinn D. B., Smits A. J. (2014). Scaling the propulsive performance of heaving flexible panels, Journal of Fluid Mechanics, 738, 250-267, https://doi.org/10.1017/ jfm.2013.597. 
6. Lighthill M. J. (1960). Note on the swimming of slender fish, Journal of Fluid Mechanics, 9(2), 305-317, https://doi. org/10.1017/S0022112060001110.

7. Morawski M., Malec M., Szymak P., Trzmiel A. (2014). Analysis of parameters of traveling wave impact on the speed of biomimetic underwater vehicle, Solid State Phenomena, 210, 273-279, https://doi.org/10.4028/www.scientific.net/ SSP.210.273.

8. Morawski M., Malec M., Zając J. (2014). Development of CyberFish - Polish Biomimetic Unmanned Underwater Vehicle BUUV, Applied Mechanics and Materials, 613, 76-82, https:// doi.org/10.4028/www.scientific.net/AMM.613.76.

9. Morawski M., Słota A., Zając J., Malec M. (2020). Fish-like shaped robot for underwater surveillance and reconnaissance - Hull design and study of drag and noise, Ocean Engineering, 217, 107889, https://doi.org/10.1016/j. oceaneng.2020.107889.

10. Piskur P., Szymak P., Flis L., Jaskólski K., Gasiorowski M. (2020). Hydroacoustic system in a biomimetic underwater vehicle to avoid collision with vessels with low-speed propellers in a controlled environment, Sensors, 20(4), 968, https://doi. org/10.3390/s20040968.

11. Piskur P., Szymak P., Flis L., Sznajder J. (2020). Analysis of a fin drag force in a biomimetic underwater vehicle, NAŠE MORE: znanstveni časopis za more i pomorstvo, 67(3), 192-198, https://doi.org/10.17818/NM/2020/3.2.

12. Piskur P., Szymak P., Sznajder J. (2020). Identification in a laboratory tunnel to control fluid velocity. In: Bartoszewicz A., Kabziński J., Kacprzyk J. (eds) Advanced, Contemporary Control. Springer, Cham, https://doi. org/10.1007/978-3-030-50936-1_128.

13. Przybylski M. (2019). Mathematical model of biomimetic underwater vehicle, Proceedings of the 33rd International ECMS Conference on Modelling and Simulation, Caserta, Italy (pp. 343-347), http://doi.org/10.7148/2019.

14. Smits A.J., 2019. Undulatory and oscillatory swimming, Journal of Fluid Mechanics, 874, P1, https://doi.org/10.1017/ jfm.2019.284.

15. Szymak P., Morawski M., Malec M. (2012). Conception of research on bionic underwater vehicle with undulating propulsion, Solid State Phenomena, 180, 160-167, https:// doi.org/10.4028/www.scientific.net/SSP.180.160.

16. Szymak P., Przybylski M., (2018). Thrust measurement of biomimetic underwater vehicle with undulating propulsion, Scientific Journal of Polish Naval Academy, 213(2), 69-82, https://doi.org/10.2478/sjpna-2018-0014.
17. Taylor G. K., Nudds R. L, Thomas A. L. R. (2003). Flying and swimming animals at a Strouhal number tuned for high power efficiency, Nature, 425, 707-710. https://doi.org/10.1038/ nature 02000 .

18. Tytell E. D., Leftwich M. C., Hsu C.-H., Griffith B. E., Cohen A. H., Smits A. J., Hamlet C, Fauci, L. J. (2016). Role of body stiffness in undulatory swimming: Insights from robotic and computational models, Physical Review Fluids, 1, 073202, https://doi.org/10.1103/PhysRevFluids.1.073202.

19. Wu X., Zhang X., Tian X., Li X., Lu W. (2020). A review on fluid dynamics of flapping foils, Ocean Engineering, 195, 106712, https://doi.org/10.1016/j.oceaneng.2019.106712.

20. Yang L., Xiao Q., Shi G., Li Wen, Chen D., Pan G. (2020). A fluid-structure interaction solver for the study on a passively deformed fish fin with non-uniformly distributed stiffness, Journal of Fluids and Structures, 92, 102778, https://doi. org/10.1016/j.jfluidstructs.2019.102778.

\section{CONTACT WITH THE AUTHORS}

\author{
Pawel Piskur \\ e-mail:p.piskur@amw.gdynia.pl \\ Polish Naval Academy \\ Smidowicza 69, 81-127 Gdynia \\ Poland \\ Piotr Szymak \\ e-mail:p.szymak@amw.gdynia.pl \\ Polish Naval Academy \\ Smidowicza 69, 81-127 Gdynia \\ Poland \\ Zygmunt Kitowski \\ e-mail:z.kitowski@amw.gdynia.pl \\ Polish Naval Academy \\ Smidowicza 69, 81-127 Gdynia \\ Poland \\ Leszek Flis \\ e-mail:l.flis@amw.gdynia.pl \\ Polish Naval Academy \\ Smidowicza 69, 81-127 Gdynia \\ Poland
}

